\title{
Lineações minerais em porfiroblastos
}

\section{Luiz Sergio Amarante Simões ${ }^{1}$ \& Frederico Guilherme Guaraldo de Andrade ${ }^{2}$}

\begin{abstract}
Resumo O estudo de lineações minerais tem fundamental importância na compreensão da evolução tectônica de cinturões orogênicos. Entretanto, em áreas polideformadas, enquanto as orientações das lineações mais novas podem ser resgatadas, as lineações antigas tendem a ser obliteradas pela superposição dos eventos deformacionais mais novos. Este artigo lança uma nova metodologia para o resgate da orientação de lineações minerais inclusas em porfiroblastos, utilizando a Platina Universal. O objetivo principal é resgatar a orientação preferencial de lineações minerais incluídas em porfiroblastos, para determinar direções de strain de uma fase de deformação antiga, cujas estruturas na matriz da rocha tenham sido obliteradas por uma fase de deformação mais nova. Considerando-se as diversas possibilidades de modificações das orientações originais de uma lineação que tenha sido incluída em um porfiroblasto, conclui-se que o resgate da orientação original é possível em porfiroblastos sintectônicos, com porções cedo tectônicas bem desenvolvidas, ou intertectônicos. A aplicação do método para o caso da porção sul da Ilha Elefante (Antártica) mostrou que as lineações resgatadas no interior dos porfiroblastos apresentam um padrão de orientação diferente da lineação mineral na matriz $\left(\mathrm{L}_{2}\right)$, corroborando a interpretação de que correspondem a $\mathrm{L}_{1}$ e indicando que a orientação preferencial de $\mathrm{L}_{1}$ é aproximadamente NNW, coerente com o modelo tectônico proposto para esta área. A consistência dos resultados obtidos atesta a eficácia do método.
\end{abstract}

Palavras-chave: lineações minerais, porfiroblastos, microtectônica.

\begin{abstract}
Mineral lineations in porphyroblasts. The study of mineral lineations has been of fundamental importance in the comprehension of tectonic evolution in orogenetic belts. However, in polydeformated areas, while the newest lineation's orientation can be found, the oldest lineations tend to be obliterated by the newest deformation events. This article launches a new methodology to the rescue of mineral lineations' orientation included within porphyroblasts, using the Universal Stage. The main objective is the rescue of preferential orientation of mineral lineations included within porphyroblasts, to determine the strain directions of an older deformation, whose structures in the matrix had been obliterated by a newer deformation event. Considering several possibilities of modifications in the original orientations of a lineation that had been included within a porphyroblast, can be concluded that the rescue of the original orientation can be possible in syntectonic porphyroblasts, in well-developed early tectonic parts, or intertectonic porphyroblasts. The aplication of the metodology in the southern part of elephant island (Antarctica) show that the lineations rescued within porphyroblasts show an orientation pattern different from the mineral lineation on the matrix $\left(\mathrm{L}_{2}\right)$, corroborating the interpretation that they correspond to $\mathrm{L}_{1}$, and indicating that the preffered orientation of $\mathrm{L}_{1}$ is aproximately $\mathrm{NNW}$, coherent with the tectonic model proposed to this area. The consistence of the results obtained attests the effectiveness of the method.
\end{abstract}

Keywords: Mineral lineations, porphyroblasts, microtectonics.

INTRODUÇÃO A importância dos porfiroblastos para estudos da evolução tectônica de cinturões orogênicos teve como marco os trabalhos de Zwart (1962, 1964), e mais recentemente, suas diversas aplicações foram listadas por Johonson (1999). Uma das grandes vantagens é a capacidade do porfiroblasto guardar em seu interior foliações anteriores ou contemporâneas ao seu crescimento, identificáveis em seções delgadas através de trilhas de inclusões solidas. Os padrões registrados por estas trilhas de inclusões foram analisados e interpretados por Zwart (1962) que os sintetizou em um quadro considerando os tipos pré-, sin- e pós-tectônicos. Mais recentemente, Passchier e Trouw (1996, 2005) apresentam uma versão, mais detalhada deste quadro, diferenciando os tipos intertectônicos e pretectônicos.

A maioria dos trabalhos de microtecônica envolvendo porfiroblastos, referem-se ao estudo de foliações preservadas em seus interiores. A partir da segunda da década de 90, surgiram diversos trabalhos que visavam resgatar a orientação da lineação de interseção de foliações dentro de porfiroblastos, lineações estas chamadas de FIA (Foliation Intersection-Inflection Axes) (Bell

1 - UNESP, Instituto de Geociências e Ciências Exatas, Departamento de Petrologia e Metalogenia, Rio Claro (SP), Brasil.

E-mail: 1simoes@rc.unesp.br

2 - UNESP, Programa de Pós-Graduação em Geologia Regional, Área de Concentração em Geologia Regional, Rio Claro (SP), Brasil.

E-mail: fredgeo@yahoo.com 
\& Kim 2004, Hickey \& Bell 1999, Aerden 2004, Bell $\&$ Chen 2002, Cihan 2004). Estruturas lineares penetrativas, de origem tectônica podem ser classificadas em quatro tipos principais: lineação de estiramento; lineação mineral; lineação de crenulação e lineação de interseção. As duas primeiras são amplamente utilizadas nas análises cinemáticas pois como marcam o eixo X do elipsóide de deformação, são, em geral, interpretadas como a direção de transporte tectônico em sistemas de cisalhamento não coaxial. Embora em algumas situações geológicas esta interpretação não seja valida (Jiang \& Williams 1988, Fossen \& Tikoff 1998), em muitos casos se aplica, como demonstrado em diversos estudos realizados em cinturões orogênicos (Valeriano et al. 2004, Uhlein 1991, Hossack \& Cooper 1986, Mattauer 1986).

Desta forma, a possibilidade de se resgatar a orientação de lineações minerais em porfiroblastos, apresenta-se como uma importante ferramenta para o estudo da cinemática de fases tectônicas anteriores ou contemporâneas ao porfiroblasto, cujas estruturas tenham sido fortemente modificadas ou totalmente obliteradas na matriz da rocha. O presente trabalho descreve uma técnica, utilizando a platina universal, para identificar e recuperar a orientação de lineações minerais preservadas na forma de inclusões em porfiroblastos.

Parâmetros Considerados Neste texto utiliza-se a classificação de Passchier \& Trouw (1996) que distingue os porfiroblastos pré-, inter-, sin- e pós-tectônicos. Destes tipos cinemáticos interessam para o presente trabalho, os inter- e os sin-tectônicos, potencialmente adequados para preservar lineações minerais pretéritas ao estágio final de formação da foliação principal da matriz.

As denominações das foliações na matriz e no interior dos porfiroblastos seguem a terminologia indicada por Passchier \& Trouw (1996), onde Se e Si referem-se às foliações na matriz e no interior do porfiroblasto, respectivamente. Analogamente, adota-se Le e Li para as lineações minerais na matriz e no porfiroblasto, respectivamente.

Para análise teórica das possibilidades de preservação de lineações minerais em porfiroblastos é considerada a hipótese de dois eventos deformacionais denominados de $\mathrm{D}_{1}$ e $\mathrm{D}_{2}$. A deformação $\mathrm{D}_{1}$ gera a foliação $\left(S_{1}\right)$ e a lineação mineral $\left(L_{1}\right)$, enquanto a deformação $\mathrm{D}_{2}$ afeta as estruturas $\mathrm{D}_{1}$, sendo a responsável pela foliação principal da matriz $\left(\mathrm{S}_{2}\right) \mathrm{e}$, por simplificação, não gera lineação mineral ou de estiramento.

Em todos os casos $\mathrm{S}_{2}$ será considerado como plano de referência para indicar se o porfiroblasto rotacionou ou não, ou seja, este será o reference frame (Jiang $\&$ Willians 2004). O mau uso da definição do reference frame por diversos autores foi reconhecido como uma das maiores deficiências nos argumentos a favor e contra a rotação de porfiroblastos (Kraus \& Willians 2001).

Análise das Possibilidades de Preservação das Orientações de Lineações Minerais em Porfiroblastos São considerados dois processos para a deformação $\mathrm{D}_{2}$ : o primeiro coaxial, gerando dobramento de $S_{1}$ e o segundo, de cisalhamento não coaxial, sem gerar dobras.

As modificações de orientação que uma lineação mineral pode sofrer após ser incluída em um porfiroblasto serão devidas à rotação das camadas/foliação e à rotação do porfiroblasto em relação à matriz da rocha hospedeira. Por isso devem ser considerados os mecanismos de dobramento, uma vez que determinam o tipo de rotação que o porfiroblasto sofrerá.

A rotação de porfiroblastos durante o dobramento tem sido bem demonstrada e argumentado na literatura (Visser \& Mancktelow 1992, Williams \& Jiang 1999, Williams \& Schoneveld 1981). Outros autores inspirados no modelo de Ramsay (1962), e invocando o processo de partição da deformação, sugerem que os porfiroblastos podem não girar durante o dobramento (Bell 1985, Bel \& Johnson 1989). Mais recentemente, Evins (2005) apresenta um quadro sintético ilustrando todos os modelos propostos na literatura indicando aqueles que implicam em rotação dos porfiroblastos. Este quadro é adotado no presente trabalho (Fig. 1) para analisar os tipos de modificações que podem ocorrer na orientação das lineações minerais inclusas em porfiroblastos. Os modelos representados são: Strain Tangencial Longitudinal (conhecido também como Flambagem ou Superfície Neutra) (Fig. 1-STL); Fluxo flexural (Fig. 1-FF); Cisalhamento Puro (Fig. 1-CP); Deslizamento Paralelo ao Plano-Axial (Fig. 1-DPA); mecanismo de dobramento proposto por De Sitter, onde além do deslizamento ao longo dos planos de $\mathrm{S}_{2}$ há encurtamento coaxial nos microlitons durante o dobramento (Fig. 1-De Sitter); Delizamento Plano-Axial Particionado, onde há domínios de deformação coaxial e não-coaxial (Fig. 1-DPAP); e Fluxo Flexural Particionado acomodado ao longo de deslizamento no plano de $\mathrm{S}_{1}$ (semelhante ao deslizamento flexural, mas adaptado para deformação heterogênea) (Fig. 1-FFP).

Observa-se que em quatro dos sete modelos apresentados (Fig. 1) ocorre a rotação dos porfiroblastos e, consequentemente, modificações na orientação de $\mathrm{Li}$, sendo que nos modelos STL, FF o eixo de rotação dos porfiroblastos serão obrigatoriamente paralelos ao eixo da dobra $\mathrm{D}_{2}\left(\mathrm{E}_{2}\right)$. Embora no caso dos mecanismos CP e DPA, esta situação nem sempre ocorra, nas análises apresentadas os eixos de rotação serão considerados paralelos a $\mathrm{E}_{2}$, por questão de simplificação.

PORFIROBLASTOS INTER-TECTÔNICOS Para os casos em que a deformação $\mathrm{D}_{2}$ gera dobras, serão considerados sete mecanismos de dobramento $\mathrm{D}_{2}$, exemplificados por Evins (2005) (Fig. 1):

São considerados dois tipos de porfiroblastos, um equidimensional (aproximadamente esférico) e outro inequidimensional, uma vez que trabalhos experimentais (Ghosh \& Ramberg, 1976) e numéricos (Passchier 1987, Holcombe \& Little 2001, Marques et al. 2005) prevêem que o comportamento cinemático é dependente da forma dos porfiroblastos.

Uma vez estabelecido o eixo de rotação dos porfiroblastos, com base nos tipos de rotação previstos para cada modelo de dobramento, pode-se determinar 

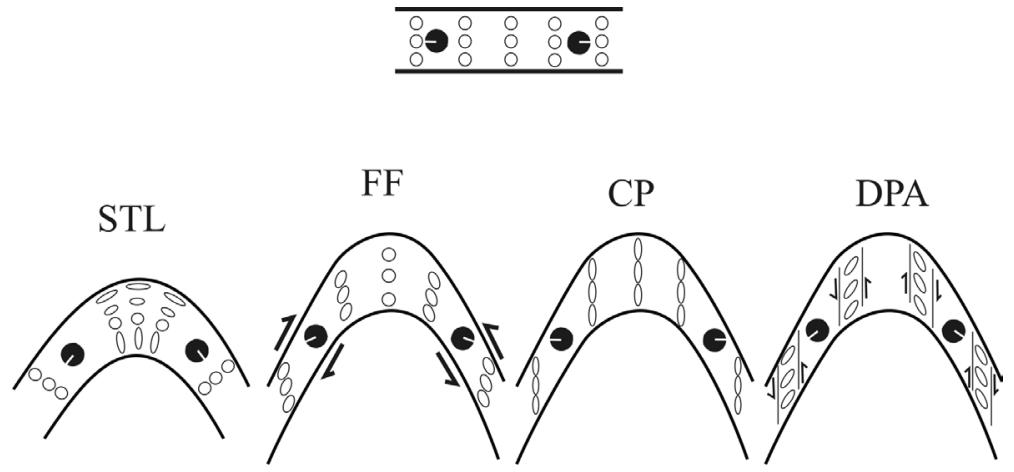

De SITTER
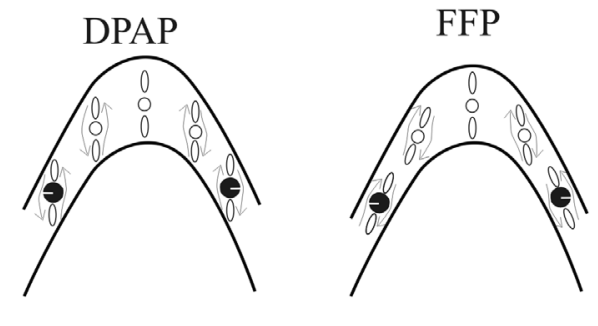

Figura 1 - Mecanismos de dobramento considerados neste trabalho. Os porfiroblastos são representados pelos círculos pretos com um traço branco para identificação de sentido e quantidade de rotação. As elipses de contorno preto são marcadores de strain na rocha. Adaptado de Evins (2005).

as possíveis posições de lineações minerais geradas numa fase $\mathrm{D}_{1}$, que tenham sido incluídas por um porfiroblasto intertectônico, girado por $\mathrm{D}_{2}$.

Para isto, utilizou-se a técnica de rotação de linhas através de rede estereográfica. Para facilitar a visualização, os estereogramas são apresentados com orientações relativas à dobra analisada cujo eixo é representado no centro do estereograma e o plano axial corresponde ao diâmetro vertical (Fig. 2). Para os casos ilustrados foram consideradas apenas dobras antiformais.

$\mathrm{Na}$ discussão dos mecanismos de dobramentos com giro dos porfiroblastos, apresenta-se a ilustração de apenas um modelo (STL, Fig. 2) a título de exemplo.

Strain TangencialLongitudinal/Flambagem(STL) O processo de strain tangencial longitudinal forma dobras pela rotação dos flancos por flexão promovendo a rotação passiva de porfiroblastos, que acompanham os flancos, alcançando rotações de no máximo $90^{\circ}$, no caso de dobras isoclinais. Por se tratar de uma rotação passiva o comportamento será idêntico tanto para minerais inequidimensionais quanto equidimensionais. A figura 2 ilustra este mecanismo mostrando três estágios, um após $\mathrm{D}_{1}$, outro após o crescimento de porfiroblastos (inter $\mathrm{D}_{1}-\mathrm{D}_{2}$ ) e o terceiro, após a formação da dobra $\mathrm{D}_{2}$ pelo mecanismo STL. Para ilustrar a possibilidade do comportamento de uma lineação mineral $\left(D_{1}\right)$ inclusa pelo porfiroblasto são mostradas as posições finais da lineação nos flancos para quatro possíveis orientações iniciais (A, B, C, e D), sendo D paralela, C perpendicular, e $\mathrm{A}$ e $\mathrm{B}$ a $45^{\circ}$ em relação ao eixo $\mathrm{E}_{2}$. Os quadriláteros com as linhas $\mathrm{A}, \mathrm{B}, \mathrm{C}$ e D, representam a foliação $\mathrm{Si}\left(=\mathrm{S}_{1}\right)$ e a lineação associada para um dado porfiroblasto, na posição inicial (pré-dobramento $\mathrm{D}_{2}$ ) e nas posições de flancos. As guirlandas nos estereogramas na parte inferior da figura representam as possíveis dispersões para um conjunto de medidas de lineações refletindo as variações da atitude dos flancos da dobra. Este esquema de representação é válido para as demais ilustrações deste trabalho.

Mecanismo de Fluxo Flexural (FF) No fluxo flexural o dobramento de uma camada é acomodado por cisalhamento simples paralelo à superfície dobrada (Williams \& Jiang 1999). A rotação de porfiroblastos é controlada pela ativação dos planos $\mathrm{S}_{1}$, que promoverá uma rotação no sentido contrário à dos flancos, sendo que este giro tende a ser compensado pela rotação dos flancos (Visser \& Mancktelow 1992). Estes autores demonstraram que o giro final do porfiroblasto, em relação a $\mathrm{S}_{2}$, tende a ser menor que o do flanco onde se encontra, e no mesmo sentido de rotação do flanco. Neste caso a Li terá comportamento semelhante ao caso STL (Fig. 2), porém definindo em estereograma guirlandas mais curtas refletindo a rotação menor do que o flanco.

Mecanismo de Cisalhamento Puro (CP) No cisalhamento puro as dobras são formadas por amplificação de deflexões naturais durante encurtamento coaxial homogêneo (Williams \& Jiang 1999). Considerando que na época de sua blastese (pós- $\mathrm{D}_{1}$ ) os porfiroblastos se formaram em orientações aleatórias, posteriormente, ao serem afetados pela deformação $\mathrm{D}_{2}$, os equidimensionais não rotacionarão, enquanto os inequidimensionais tenderão a rotacionar para o plano de $\mathrm{S}_{2}$ em função do 

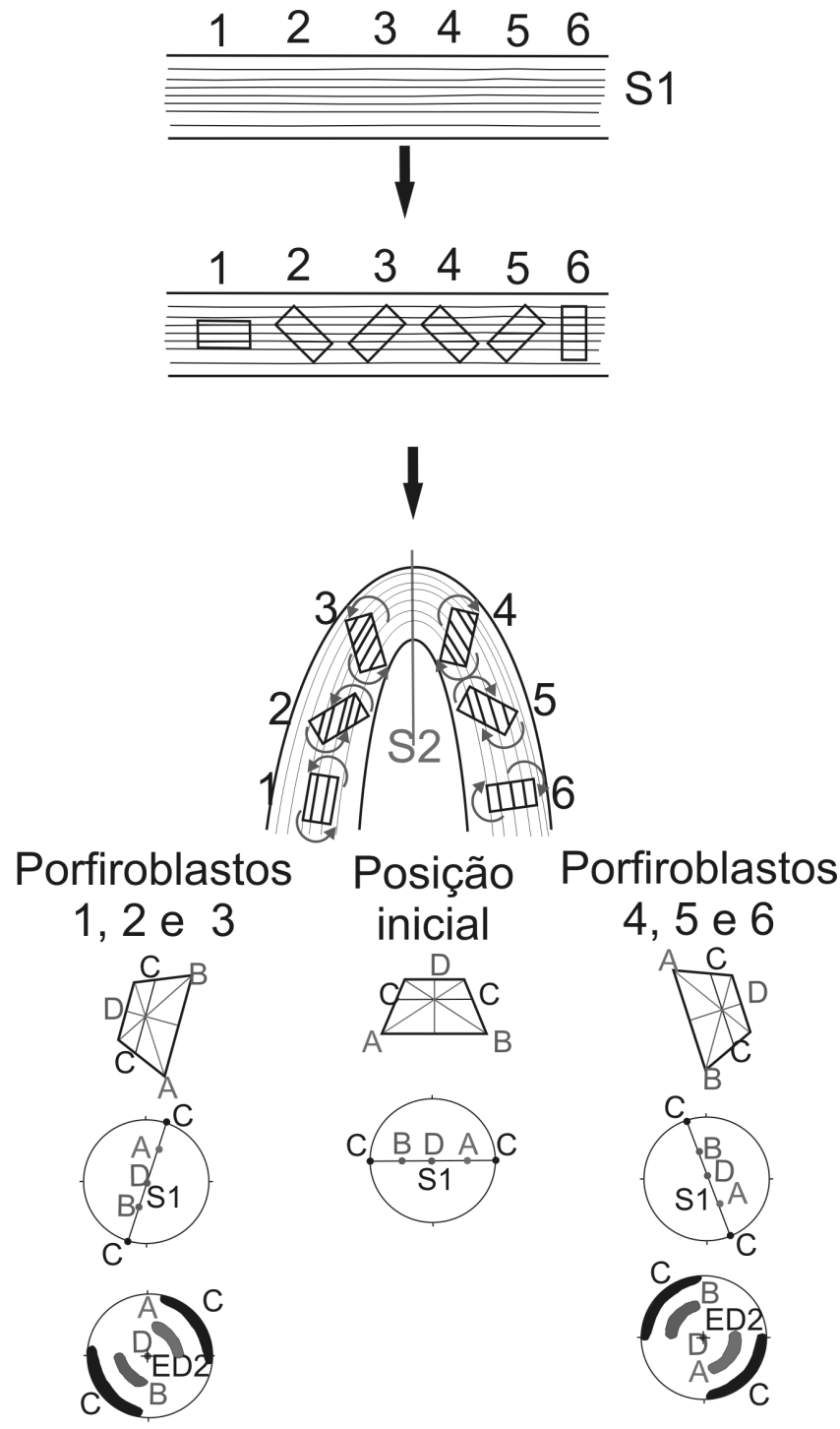

Figura 2 - Exemplo teórico do comportamento de porfiroblastos inequidimensionais por strain tangencial longitudinal. O eixo de rotação é igual ao eixo da dobra, que se situa no centro do estereograma. O diâmetro vertical do estereograma corresponde ao plano axial da dobra $\left(S_{2}\right)$ e as projeções são no hemisfério inferior. São mostradas as posições finais da lineação nos flancos para quatro possíveis orientações iniciais $(A, B, C$, e D), sendo $D$ paralela, $C$ perpendicular, e $A$ e $B$ a $45^{\circ} \mathrm{em}$ relação ao eixo (ED). Os quadriláteros com as linhas $A, B, C$ e $D$, representam a foliação $S i\left(=S_{p}\right)$ e a lineação associada para um dado porfiroblasto, na posição inicial (pré-dobramento $D_{2}$ ) e nas posições de flancos. As dispersões nos estereogramas inferiores representam as posições de lineações possíveis para um conjunto de porfiroblastos ao longo de diferentes inclinações dos flancos.

achatamento. Com isso, poderão rotacionar em sentidos distintos, mesmo em um único flanco e com quantidades de giros distintas, dependendo de sua orientação original. Porfiroblastos esféricos não irão rotacionar e as lineações preservadas no plano de Si irão manter a sua posição inicial. Para o caso dos porfiroblastos inequidimensionais os eixos de rotação podem não coincidir com os eixos das dobras, pois dependem da orientação das faces maiores em relação a Si. Nestes, os padrões de orientação das lineações podem ser complexos e deverão mostrar dispersão em diversas direções.

Mecanismo de Deslizamento PlanoAxial(DPA) Neste mecanismo as dobras são formadas por cisalhamento dos flancos, paralelo ao plano axial. O porfiroblasto rotacionará sinteticamente aos flancos e na zona de charneira tenderá a não rotacionar. Neste modelo a rotação máxima dos porfiroblastos pode ser praticamente infinita (Willians \& Jiang 1999) e causará a rotação das lineações inclusas em torno do eixo de vorticidade definindo trajetórias circulares para as lineações originalmente oblíquas a este eixo. Este eixo de rotação só será paralelo ao eixo da dobra $\mathrm{D}_{2}$ quando a orientação de original de $\mathrm{S}_{1}$ for perpendicular à direção do cisalhamento. Os porfiroblastos inequidimensionais terão comportamento semelhante, porém tenderão rotacionar somente até se paralisarem ao plano de cisalhamento $\left(\mathrm{S}_{2}\right)$, que é o plano atrator (Passchier \& Trouw 2005).

Mecanismos proposto por De Sitter, Deslizamento Plano Axial Particionado (DPAP) e de Fluxo Flexural Particionado (FFP) Nestes modelos, em função da partição da deformação, tanto porfiroblastos esféricos quanto inequidimensionais não rotacionam (Johnson 1999) e quaisquer orientações originais de $\mathrm{L}_{1}$ inclusas nos porfiroblastos se mantêm inalteradas. A partição de deformação envolve cisalhamento não-coaxial nos planos de $\mathrm{S}_{2}$ ou de $\mathrm{S}_{1}$, mantendo os domínios onde ocorrem os porfiroblastos preservados da deformação não coaxial, e consequentemente sem rotação. A título de exemplo destes casos o modelo proposto por Bell (1985) é ilustrado na figura 3, mostrando o desenvolvimento de zonas de concentração das deformações coaxial e não-coaxial, onde os porfiroblastos por ocorrerem preferencialmente nas zonas de deformação coaxial, não rotacionam.

Possibilidades sem Formação de Dobras Para este caso assume-se que $\mathrm{D}_{2}$ corresponde a um cisalhamento não coaxial que reativa $S_{1}$. Os porfiroblastos inequidimensionais em regime de cisalhamento não coaxial, tendem a rotacionar até o paralelismo com o plano de cisalhamento. $\mathrm{O}$ eixo de rotação corresponderá ao vetor de vorticidade do cisalhamento. Para porfiroblastos esféricos a quantidade de rotação será proporcional à deformação cisalhante e, por isso pode ser grande, pois devido ao seu formato, tendem a girar indefinidamente, enquanto durar a deformação (Schoneveld 1977, Passchier \& Trouw 2005). Considerando uma deformação homogênea, os porfiroblastos rotacionarão a mesma taxa, já para uma deformação heterogênea, a quantidade de giro pode ser diferente de um porfiroblasto para outro.

PORFIROBLASTOS SIN-TECTÔNICOS Para a análise do comportamento das lineações em porfiro- 


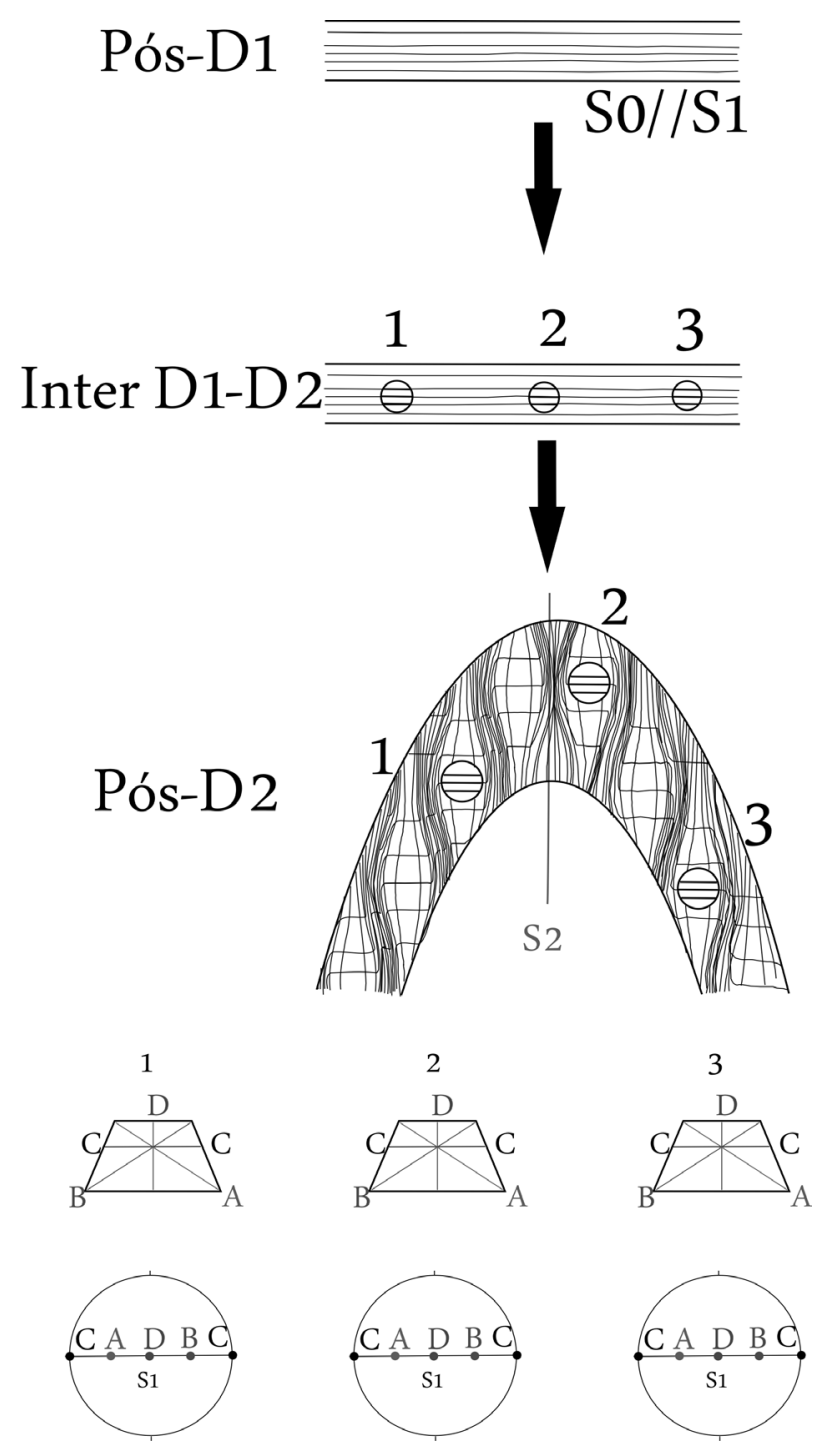

Figura 3 - Geometria de inclusões de porfiroblastos esféricos $D_{2}$ para o mecanismo de dobramento com partição da deformação nos planos de $S_{2}$. Os retângulos em perspectiva representam a foliação $\mathrm{Si}\left(=S_{1}\right)$ no interior dos porfiroblastos (1, 2 e 3). Como não há rotação, as lineações não definem guirlandas.

blastos sintectônicos, considerou-se que a história de crescimento envolve estágios de cedo a tarde tectônico. As previsões teóricas estabelecidas evidenciam que os estágios cedo-tectônicos são os mais adequados para resgatar a orientação original das lineações inclusas. Para os demais estágios as modificações impostas pela deformação $\mathrm{D}_{2}$ e as diversas possibilidades de reorientação em funçã̃o de acomodações locais em torno das faces do porfiroblasto em desenvolvimento, podem conduzir a um complexo padrão de orientação, inviabilizando o resgate da orientação original das lineações minerais inclusas no porfiroblasto.

Uma lineação mineral inclusa em um porfiroblasto no estágio cedo tectônico terá comportamento praticamente idêntico à de um porfiroblasto inter-tectô- nico, apresentando apenas um pouco mais de dispersão das medidas devido às modificações causadas pelos estágios iniciais da fase $\mathrm{D}_{2}$.

Dentre os porfiroblastos sintectônicos, exige uma análise específica o caso do padrão espiralado causado pela rotação do porfiroblasto que é o caso das granadas conhecidas como snowball (Zwart 1962, Schoneveld 1977).

O processo de formação de granadas snowball foi demonstrado por Schoneveld (1977), onde a rotação do porfiroblasto sintectônico em regime de cisalhamento não-coaxial promove a inclusão das porções da foliação adjacentes à medida que cresce, originando uma geometria em espiral, podendo ser utilizados como indicadores de sentido de cisalhamento. Aqui, para a análise do comportamento da lineação a ser incluída, se considera uma única fase de deformação não-coaxial, do tipo cisalhamento simples, gerando uma foliação $\left(\mathrm{S}_{1}\right)$ e lineação mineral $\left(\mathrm{L}_{1}\right)$ subparalela à direção de cisalhamento. Neste caso, a lineação mineral no momento em que for incluída será aproximadamente paralela à direção de cisalhamento e será rotacionada em torno de um eixo perpendicular à direção de cisalhamento. O maior giro é registrado no núcleo do cristal havendo uma diminuição progressiva para as bordas. Apresentando a foliação $\left(\mathrm{S}_{1}\right)$ como um traço horizontal e a direção de $\mathrm{L}_{1}$ na extremidade do estereograma, contida em $\mathrm{S}_{1}$, após rotação sintectônica apresentará uma dispersão predominantemente ao longo da borda do estereograma.

A lineação inclusa pode apresentar variações na direção devido a acomodações pré-inclusão, ao redor do porfiroblasto em crescimento. Entretanto a lineação inclusa tenderá a indicar, preferencialmente, a direção de cisalhamento. Já o caimento apresentará modificações significativas.

\section{DETERMINACÃ̃O DE LINEACÕES MINERAIS} EM PORFIROBLASTOS O objetivo principal é resgatar a orientação preferencial de lineações minerais incluídas em porfiroblastos, para determinar direções de strain de uma fase de deformação antiga, cujas estruturas na matriz da rocha tenham sido obliteradas por uma fase de deformação mais nova. O método consiste na leitura de orientações das inclusões em lâmina delgada através da platina universal, de acordo com o procedimento descrito a seguir. Para isso, e considerando os aspectos apresentados no item anterior, as rochas a serem estudadas precisam ter: (a) Porfiroblastos com inclusões de minerais prismáticos e/ou aciculares (ex. rutilo, epidoto, turmalina); (b) Conhecimento geológico consolidado da relação deformação x metamorfismo; (c) Porfiroblasto hospedeiro da lineação, a serem estudados, devem ser sintectônicos, com estágio cedo tectônico bem preservado, ou intertectônicos.

A seleção das amostras depende, em parte, da história tectônica específica da área a ser estudada, devendose trabalhar sempre com amostras orientadas. Na definição dos cortes para a confecção das lâminas, busca-se um que seja perpendicular ao eixo de rotação dos porfiroblastos, e por isso, em geral, deve-se considerar duas situa- 
ções distintas: 1) dominada por dobramento e 2) relacionada a zonas de cisalhamento dúctil. No primeiro caso as lâminas devem ser executadas em cortes perpendiculares aos eixos das dobras. $\mathrm{O}$ levantamento da Li considerando separadamente cada setor da dobra (flancos e charneira) é interessante e deve ser feito, pois auxilia na compreensão do processo de rotação sofrido pela lineação. Lâminas paralelas ao eixo e perpendiculares ao plano axial, embora não sejam obrigatoriamente necessárias, são úteis para confirmação das leituras das lineações. No caso das zonas de cisalhamento dúcteis, os cortes devem ser perpendiculares à foliação principal e paralelos à lineação de estiramento. Adicionalmente um outro corte perpendicular a este pode ser interessante para confirmação dos resultados obtidos no primeiro corte. Nos casos em que a Li tenha sido girada, as medidas feitas nos cortes perpendiculares ao eixo de rotação, produzirão estereogramas mais fácies de serem interpretados.

Em seguida à confecção da lâmina, são escolhidos porfiroblastos cujas direções das trilhas de inclusões sejam representativas de toda a lâmina. Em geral, mas principalmente no caso dos sintectônicos, são preferencialmente escolhidos os porfiroblastos de maior tamanho para a medição das lineações, visto que as inclusões da borda tendem a estar mais rotacionadas, e os porfiroblastos menores podem, na verdade, ser cortes na borda de um porfiroblasto grande. No presente estudo foram utilizados seis porfiroblastos por lâmina e para cada porfiroblasto foram escolhidas dez inclusões. Os minerais a serem medidos devem ser prismáticos e/ou aciculares, situados na região central do porfiroblasto. São utilizadas, preferencialmente, as inclusões com comprimento menor ou igual a 30 microns, (espessura da lâmina). Esse limite é estabelecido, pois inclusões maiores, orientadas em alto ângulo com a lâmina podem aparentar uma orientação paralela ao corte, conduzindo a erros.

\section{Medição das Orientações das Inclusões com Auxílio da}

Platina Universal A metodologia de leitura desenvolvida para medir lineações minerais em porfiroblastos exige a calibração padrão do alinhamento dos eixos da platina e ajuste da altura da lâmina, como descrito em vários livros didáticos (por exemplo: Passchier \& Trouw 2005).

Após a calibração da platina, para determinação das lineações inclusas nos porfiroblastos segue-se o procedimento descrito abaixo, usando-se as referências da figura 4.

1- Com os eixos zerados, define-se uma linha na lâmina que corresponderá ao norte de referência (NR), que deverá ser posicionada apontando para o "norte" da platina universal. Usa-se o acessório de esquadro para encaixe da lâmina, para manter a orientação da lâmina constante ao se deslocar de um campo de visão para o outro. No presente estudo, utilizou-se a maior dimensão da lâmina como a direção NS de referência. Utilizar a direção da foliação principal ou plano axial da dobra para marcar a linha NR, facilita a visualização dos resultados.

2- A medida do azimute da lineação é feita em graus, no eixo $\mathrm{A}_{1}$, rotacionando o eixo pelo menor ângulo até o paralelismo do comprimento maior do mine-

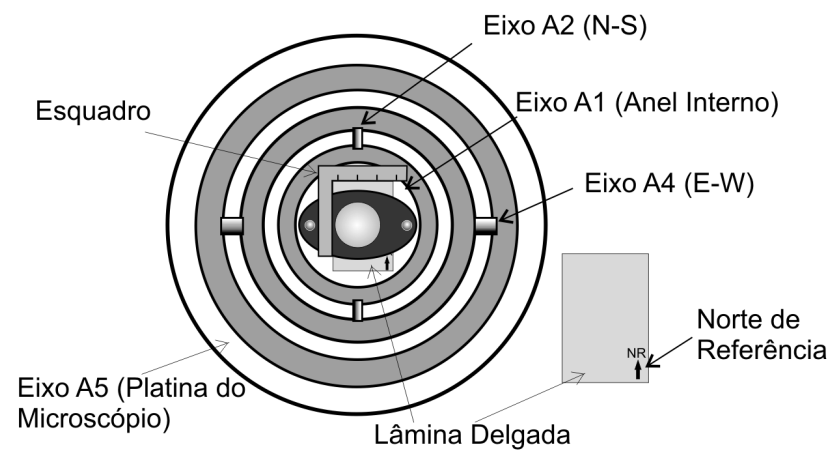

Figura 4 - Ilustração dos eixos da Platina Universal, onde foram feitas as medidas de lineações inclusas nos porfiroblastos estudados. A figura ilustra uma platina universal, onde estão indicados os ei$\operatorname{xos} A_{1}, A_{2}, A_{4}$ e $A_{5}$. Mantendo-se fixo eixo $A_{5}$ (platina do microscópio), a orientação das lineações é obtida através do giro em torno dos eixos $A_{1}$ (vertical) e $A_{4}$ (horizontal), na posição $E W$ da platina.

ral prismático (que define $\mathrm{Lm}$ ) com a direção do retículo NS (//A $)$.

3- Uma rotação para a direita ou esquerda no eixo $\mathrm{A}_{2}$ (NS) permitirá a visualização da terceira dimensão da lineação e indicará, com maior clareza, qual o sentido de mergulho. Essa rotação de $\mathrm{A}_{2}$ é apenas para constatação preliminar da direção de mergulho das inclusões. Para leitura do valor de mergulho, o eixo $\mathrm{A}_{2}$ deve permanecer em zero.

4- Nessa etapa deve-se tomar uma atenção especial na inversão da imagem produzida pelo microscópio. A depender do modelo utilizado, a imagem pode aparecer invertida como em um espelho ou invertida com o topo virado para baixo. No modelo utilizado neste trabalho, a inversão ocorre como em um espelho e, conseqüentemente a medida deve ser corrigida. A correção é feita contando-se a variação em graus que foi lida, a partir de zero, para o outro lado. Por exemplo, uma leitura de azimute $022^{\circ}$, devido à inversão é, na verdade $338^{\circ}$, relativo a NR. Neste ponto, a lineação inclusa está na direção N-S (em relação a platina, referência adotada no passo 5). Obtido o valor do azimute da inclusão, resta definir o valor de caimento.

5- A leitura do valor de caimento é feita no eixo $\mathrm{A}_{4}$ (EW). Move-se o eixo A4 na direção do observador (para S, referente ao $\mathrm{N}$ da platina) ou na direção oposta ao observador (para N), até que o cristal observado atinja o maior comprimento observado. Nessa situação, uma ocular com retículos graduados é de grande ajuda. A medida de mergulho nem sempre poderá ser determinada com exatidão desta forma, pois a construção da platina universal não permite a leitura de medidas maiores do que $50^{\circ} \mathrm{em} \mathrm{A}_{4}$. Caso a leitura não seja possível, a inclusão deve ser levada neste mesmo eixo $\left(\mathrm{A}_{4}\right)$ até a posição de menor comprimento. Nesta posição, $\mathrm{o}$ ângulo de mergulho é a medida complementar ao ângulo que o eixo $\mathrm{A}_{4}$ foi rotacionado.

6- Se o valor foi obtido através da horizontali- 
zação do cristal (maior comprimento), o sentido de caimento deve ser oposto ao rumo de mergulho da platina (observado diretamente no corpo do microscópio). Neste estágio tem-se a direção e o caimento da inclusão.

7- Se o valor de caimento for para $\mathrm{S}$ (em relação à platina), então o valor de azimute da direção deve ser corrigido subtraindo-se ou adicionando-se $180^{\circ}$ à leitura. Essa inversão é realizada pelo fato do caimento para sul apontar na direção oposta à do azimute corrigido no passo 4 .

Uma vez feita a leitura da orientação das inclusões que definem Li, elabora-se para cada lâmina um estereograma onde o plano do equador é paralelo à lâmina e o N corresponde à orientação NR marcada na lâmina (passo 1) e o respectivo diagrama de contorno estrutural, que indicará a orientação preferencial da Li para cada lâmina. Neste estágio já se visualiza a orientação preferencial de Li em relação aos principais elementos estruturais da rocha (foliação principal, plano axial e eixo da dobra), que também podem ser representados no estereograma.

A partir deste ponto, os valores plotados nos estereogramas são rotacionados para resgatar suas posições geográficas reais (em relação ao norte verdadeiro) reconstituindo-se a posição das leituras com a posição da lâmina na amostra e da amostra no espaço. Isto pode ser feito através de rotações em estereogramas, uma vez que se conhece a atitude do plano de corte da lâmina e da linha de referência (NR) da lâmina na amostra. Opcional- mente, pode-se recorrer a uma medição direta através do posicionamento da amostra orientada em caixa de areia.

APLICAÇÃO NA ILHA ELEFANTE - ANTÁRTI-

CA Como teste para o método, foram utilizadas rochas da Ilha Elefante, localizada no extremo norte da Península Antártica, sendo uma das ilhas do Arquipélago Shetland do Sul (Fig. 5). A Ilha Elefante se situa na região do Arco de Scotia, que abriga rochas do Complexo Metamórfico de Scotia, com idades de metamorfismo entre o Cenozóico e o Paleozóico Superior, indicando idades mais antigas de sudoeste (50 Ma, Ilha Smith) para nordeste (110-90 Ma, Ilha Elefante, e 200-180 Ma, Arquipélago Orcadas do Sul) (Trouw et al. 2000).

As rochas presentes na Ilha Elefante consistem predominantemente de metassedimentos siliciclásticos (metapelitos) e localmente químicos (metacherts e mámores), associados a metavulcânicas básicas toleíticas, tipo MORB (Trouw et al. 2000).

Três fases de deformação são registradas na Ilha Elefante (Grunow et al. 1992, Trouw et al. 2000). $\mathrm{D}_{1}$ gerou uma foliação $\mathrm{S}_{1}$ caracterizada como uma clivagem ardosiana de orientação aproximada E-W e mergulho de alto ângulo predominantemente para norte, associada a forte lineação mineral e/ou de estiramento. Esta deformação originou dobras apertadas afetando a estratificação primária $\mathrm{S}_{0}$. As estruturas $\mathrm{D}_{1}$ são melhor

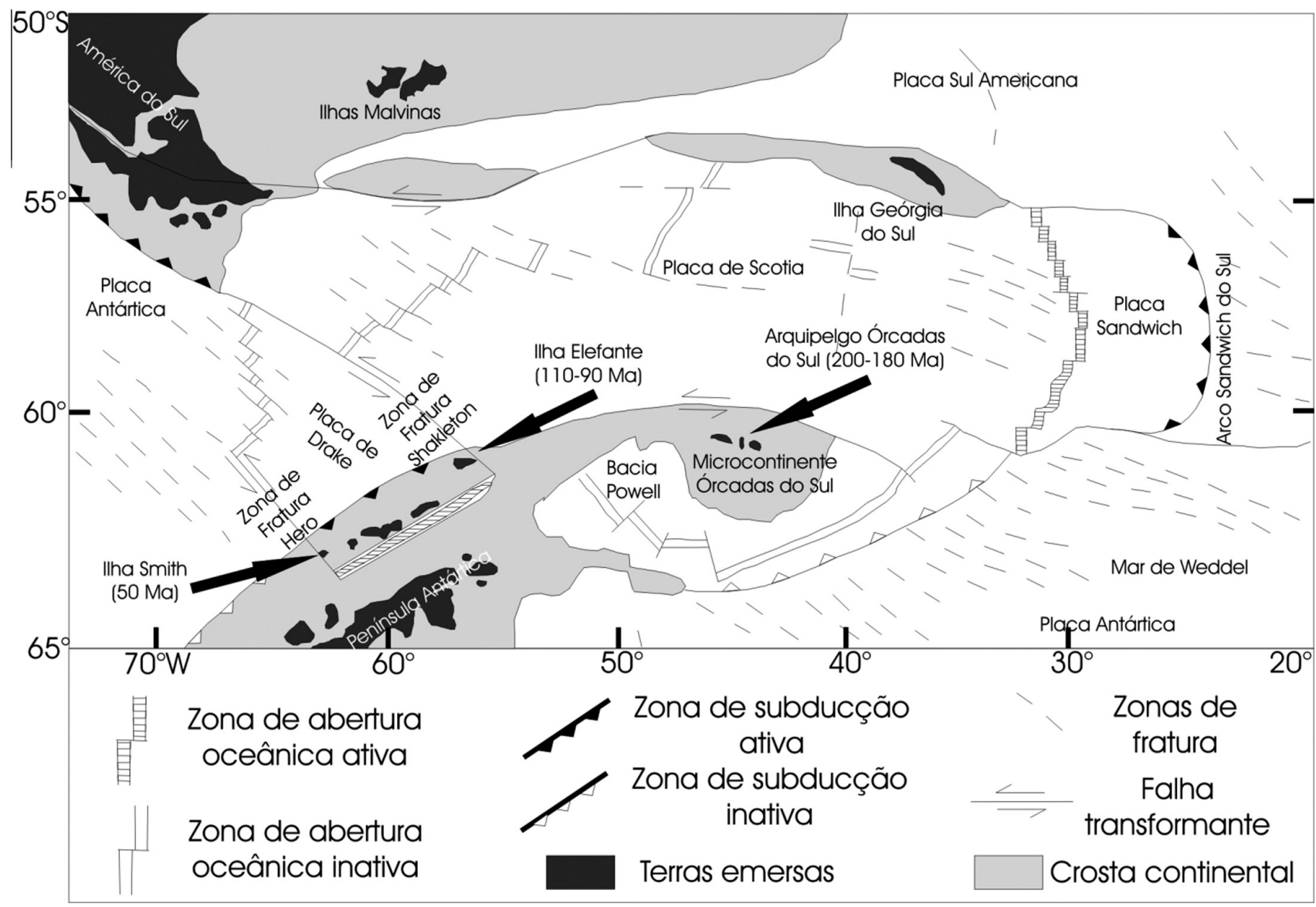

Figura 5 - Situação da Ilha Elefante no quadro tectônico da região do Arco de Scotia. Adaptado de Trouw et al. (2000). 
identificadas no norte da Ilha Elefante (Fig. 6), onde a deformação $\mathrm{D}_{2}$ foi menos intensa.

As estruturas $\mathrm{D}_{2}$ apresentam um gradiente de intensidade crescente do norte, onde são pouco presentes, para sul, onde são praticamente dominantes. No norte da ilha a deformação $\mathrm{D}_{2}$ resume-se a dobras abertas a apertadas com clivagem plano-axial pouco desenvolvida. No sul as dobras $\mathrm{D}_{2}$ são apertadas, com xistosidade planoaxial forte $\left(\mathrm{S}_{2}\right)$ de direção preferencial WSW-ENE com mergulho alto, principalmente para NNW, associada a uma lineação mineral/estiramento mergulhando $10-30^{\circ}$ para WSW paralela ao eixo de dobras $\mathrm{D}_{2}$ (Fig. 7). Esse aumento de intensidade no desenvolvimento das estruturas $\mathrm{D}_{2}$, de norte para sul, acompanhado do aumento do metamorfismo foi interpretado por Trouw et al. (2000) como uma deformação $\mathrm{D}_{2}$ mais intensa acompanhada de maior temperatura no sul da ilha.

A deformação $\mathrm{D}_{3}$ gerou crenulações, dobras locais e kink bands centimétricos a métricos, muitos com eixos e planos axiais íngremes, de direção NE-SW a NW-SE que se formam isolados e em pares conjugados (Trouw et al. 2000).

As rochas da Ilha Elefante correspondem a um prisma acrescionário, com registro metamórfico sin- $\mathrm{D}_{1}$ de fácies xisto azul na porção norte da ilha, indicado por cristais de crossita e glaucofana, que juntamente com epidoto marcam uma lineação mineral $\mathrm{L}_{1}$. Acompanhando o gradiente deformacional $\mathrm{D}_{2}$, o metamorfis- mo associado a esta segunda fase mostra aumento de intensidade de norte para sul, evidenciado pela escassez e pequeno tamanho dos cristais de albita no norte, que tornam-se progressivamente mais abundantes e maiores para o sul, e passam a exibir bordas de oligoclásio no extremo sul da ilha (Trouw, Simões e Valadares 1998, Trouw et al. 2000).

A presença do gradiente deformacional e metamórfico $\mathrm{D}_{2}$ faz com que esta área seja ideal para se testar o método de resgate de orientação de lineações minerais, pois os porfiroblastos de albita na porção sul da ilha apresentam fase cedo- $\mathrm{D}_{2}$ bem marcada (dada por trilhas de inclusões definindo $\mathrm{Si}=\mathrm{S}_{1}$, reta a levemente ondulada) enquanto as estruturas $D_{1}$ na matriz são fortemente obliteradas por $\mathrm{D}_{2}$. Além disso, na porcão norte da ilha tem-se a lineação $\mathrm{L}_{1}$ bem preservada, embora sua orientação original tenha sido modificada por $\mathrm{D}_{2}$.

Amostras Estudadas As amostras estudadas pertencem a parte sul da ilha, onde a deformação e recristalização mais intensas durante $\mathrm{D}_{2}$ obliteram quase totalmente as estruturas $\mathrm{D}_{1}$. Foram estudados xistos cinzas e rochas metabásicas, ricos em porfiroblastos de albita. O xisto cinza é composto por uma matriz de muscovita, biotita, clorita, epidoto e quartzo, contendo porfiroblastos de granada e albita. Também ocorrem pequenos cristais de grafita em proporções variadas, formando por vezes camadas grafitosas. Intercalados nos xistos

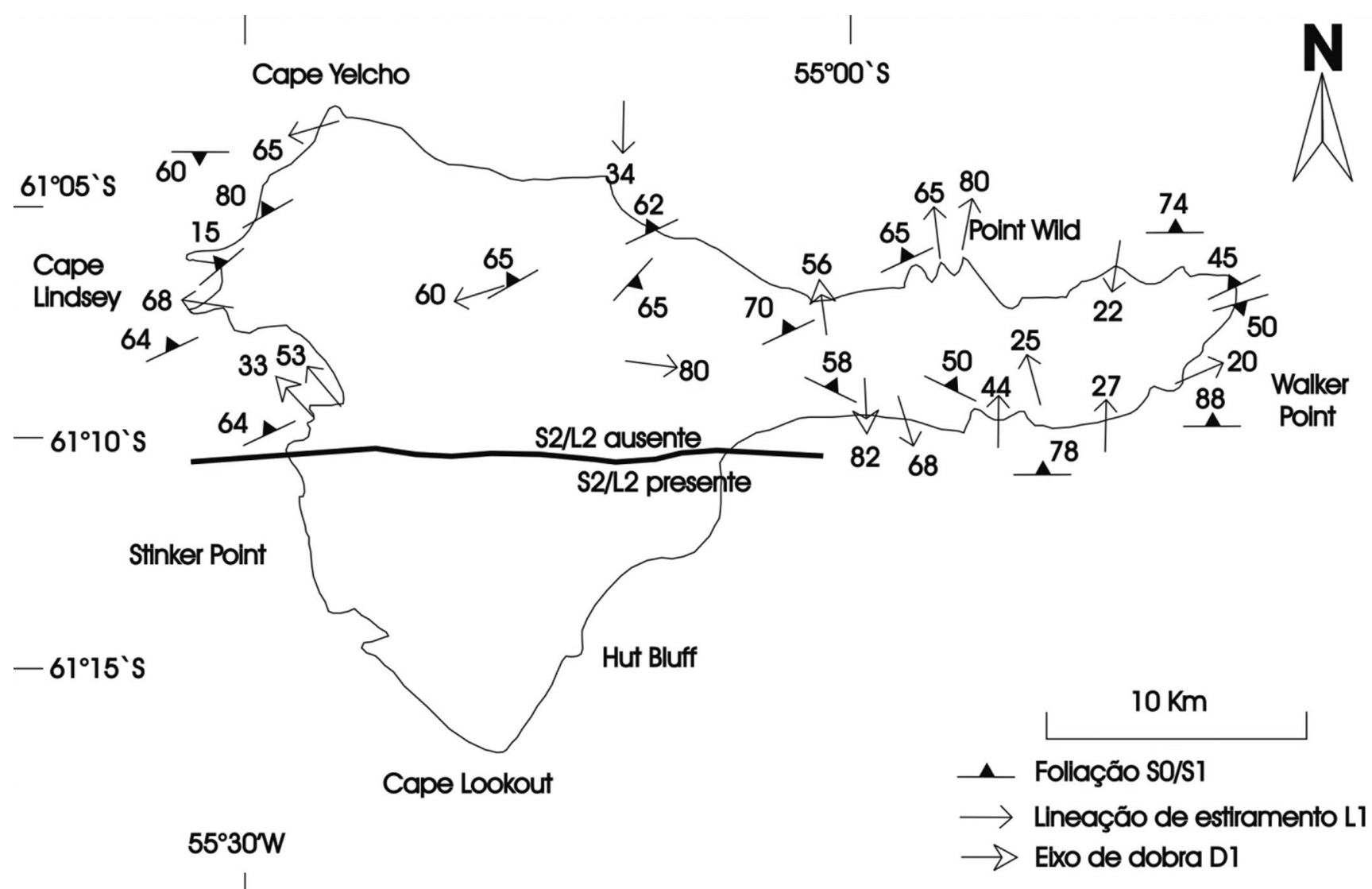

Figura 6 - Mapa estrutural da Ilha Elefante, destacando as estruturas $D_{I}$, melhor preservadas no norte da ilha. Adaptado de Trouw el al. (2000) e Grunow et al. (1992). 


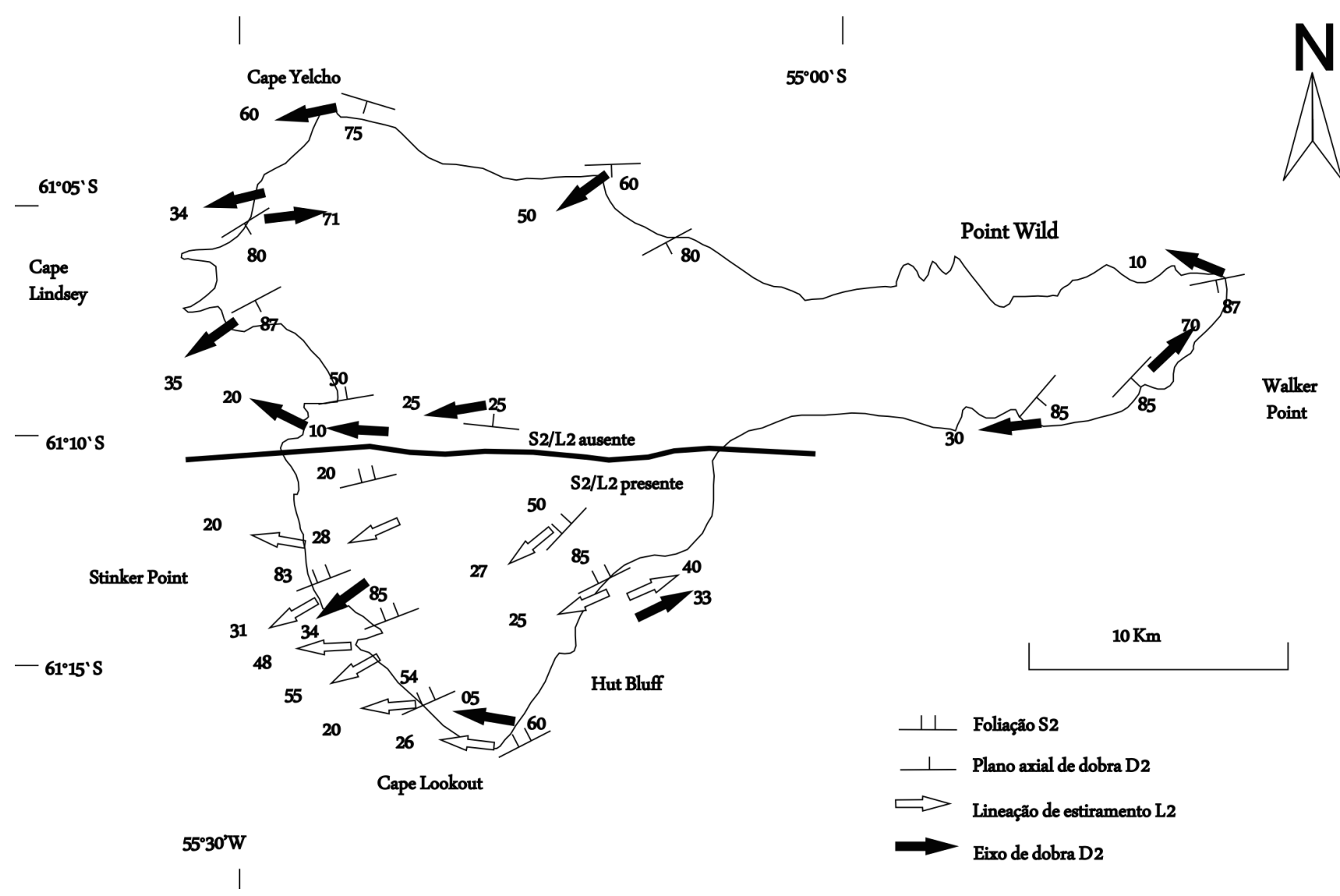

Figura 7 - Mapa estrutural da Ilha Elefante, destacando as estruturas $D_{2}$ mais presentes no sul da ilha. Adaptado de Trouw et al. (2000) e Grunow et al. (1992).

ocorrem também níveis milimétricos a centimétricos de metachert com quartzo, carbonato, pouca albita e clorita, além de pequenas granadas.

Os porfiroblastos de albita são subheudrais e têm padrão de inclusões predominantemente sigmoidais $(60 \%)$, seguido pelo padrão de inclusões retas $(30 \%)$, sendo que $8 \%$ não têm padrão definido e $2 \%$ tem padrão de estrutura milípede (Simões et al. 2003). As inclusões nestes porfiroblastos de albita são de quartzo, epidoto, opacos (grafita), granadas euhedrais e localmente, na porção central da ilha, de anfibólio verde azulado. Os traços de inclusões de Si são contínuos com a foliação $\mathrm{S}_{1}$ da matriz da rocha, em geral, transposta por dobramento apertado para o plano $\mathrm{S}_{2}$, devido à deformação $\mathrm{D}_{2}$ (Fig. 8). Os cristais de albita, por vezes incluem dobras suaves a abertas da fase $\mathrm{D}_{2}$, enquanto na matriz estas dobras são mais apertadas e com foliação plano axial $\mathrm{S}_{2}$ (Trouw et al. 1986). O padrão predominante de inclusões retas no centro e curvas na borda levou à interpretação de que estes porfiroblastos são inter a sintectônicos à fase $\mathrm{D}_{2}$ (Trouw et al. 2000).

$\mathrm{O}$ arranjo espacial de $\mathrm{Si}$ indica que dos porfiroblastos de albita começaram a crescer em estágio pré ou cedo $\mathrm{D}_{2}$, incluindo em seu núcleo a foliação $\mathrm{S}_{1}$ próxima de sua posição original. As trilhas de inclusões nas bordas, na continuidade da blastese, evidenciam $\mathrm{S}_{1}$ progressivamente rotacionada para o paralelismo com
$\mathrm{S}_{2}$, devido ao dobramento $\mathrm{D}_{2}$. $\mathrm{O}$ arranjo geométrico observado (Fig. 8) indica que houve pouca rotação dos porfiroblastos de albita durante $\mathrm{D}_{2}$ (Simões et al. 2003), o que permite resgatar em seu núcleo as orientações originais de $S_{1}$ e da lineação $L_{1}$ preservadas próximas de suas posições originais.

Foram estudadas oito amostras da ilha Elefante, seis delas distribuídas ao longo de um perfil feito na região de Stinker Point, situadas no sul da ilha (Fig. 9). Ao longo deste perfil a relação angular entre $\mathrm{S}_{2}$ e $\mathrm{S}_{0} / / \mathrm{S}_{1}$ mantém-se aproximadamente constante, correspondendo a assimetria de flanco sul de uma sinforma. $\mathrm{O}$ ângulo entre estas estruturas aumenta na porção $\mathrm{N}$ do perfil, indicando aproximação de uma zona de charneira $D_{2}$. Das oito amostras selecionadas, foram feitas quatorze lâminas, medidas 10 lineações por porfiroblasto (indicadas pela orientação de cristais prismáticos/aciculares de epidoto) e 6 porfiroblastos por lâmina, resultando em um conjunto de 840 medidas. Outras medidas adicionais foram feitas em porfiroblastos com Si paralelo a $\mathrm{S}_{2}$, totalizando 928 medidas de lineação.

As amostras estudadas têm diferentes números de corte, feitos em diferentes posições:

- EL-03-36-E: a localidade corresponde a uma zona de charneira de dobra $\mathrm{D}_{2}$ (onde $\mathrm{S}_{2}$ faz alto ângulo com $\mathrm{S}_{1}$ ) com duas lâminas perpendiculares ao plano axial $\left(\mathrm{S}_{2}\right)$, sendo uma paralela (Fig. 11, posição 4) e outra 



Figura 8 - Fotomicrografias ilustrando o padrão típico de inclusão dos porfiroblastos de albita nas rochas estudadas. A imagem central é uma fotomicrografia de dobra $D_{2}$, deformando $S_{\gamma} / S_{1}$ em xisto cinza, com desenvolvimento de foliação plano axial $\left(S_{2}\right)$. A base da foto corresponde aproximadamente a $3 \mathrm{~cm}$. Os detalhes dos porfiroblastos de albita mostram as diferentes assimetrias no padrão de inclusões, em $S$ e em $Z$, com as trilhas de inclusões definindo $\mathrm{Si}\left(=S_{1}\right)$ com padrão sigmoidal, marcada por cristais prismáticos de epidoto. As fotos dos porfiroblastos com assimetria em detalhe tem $0,35 \mathrm{~mm}$ na base.
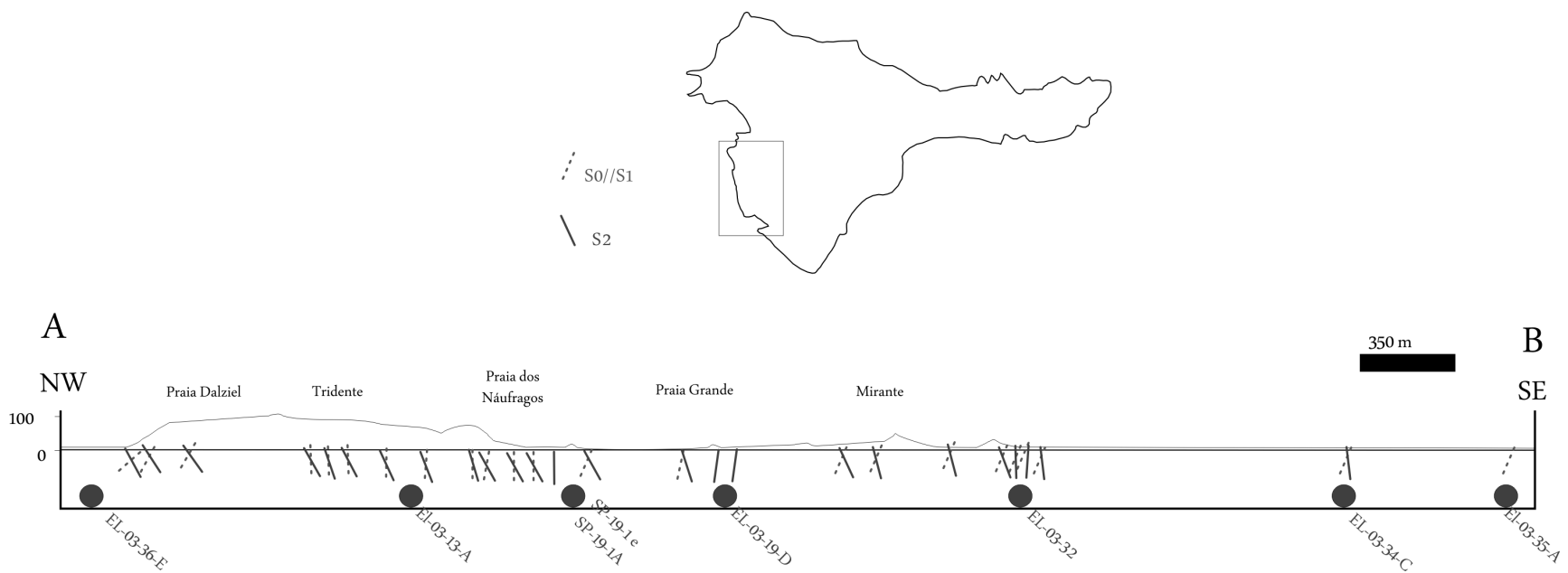

Figura 9 - Perfil geológico simplificado mostrando a relação S1/S2 na região de Stinker Point, com a localização das amostras estudadas no perfil e indicação da topografia adjacente à linha de costa.

perpendicular ao eixo da dobra $\mathrm{D}_{2}$ (Fig. 11, posição 1).

- EL-03-13A, EL-03-19D e EL-03-32: amostras de dobras $\mathrm{D}_{2}$ (escala centimétrica), com duas lâminas cada, ambas em planos perpendiculares ao plano de $\mathrm{S}_{2}$ e ao eixo da dobra, sendo uma em cada flanco para as duas primeiras amostras (Fig. 11, posições 2 e 3 ) e para a amostra EL-03-32 que corresponde a uma dobra assimétrica, as duas lâminas foram obtidas dos flancos longos, tendo assim uma mesma assimetria.

- SP-19-1 e SP-19-1A: duas amostras do mesmo ponto, em que $\mathrm{S}_{1}$ e $\mathrm{S}_{2}$ são subparalelos, tendo dois cortes perpendiculares a foliação $\mathrm{S}_{2}$, um paralelo a lineação $L_{2}$ (e conseqüentemente ao eixo $D_{2}$ ) e outro perpendicular (Fig. 11, números 5 e 6 respectivamente).

- EL-03-34C e EL-03-35: duas amostras de dobras $\mathrm{D}_{2}$, com duas lâminas cada, feitas na zona de charneira (Fig. 11, posição1).
A figura 10 mostra em mapa a posição do perfil e das lineações, tanto em campo como medidas nos porfiroblastos, além das medidas de foliação inclusa.

Seis das amostras estudadas correspondem a xistos cinza (metapelitos) e duas correspondem a rochas metabásicas (SP-19-1 e SP-19-1A).

O padrão de inclusões sigmoidais das albitas apresenta, sistematicamente, assimetria em S para o flanco direito de antiformas $\mathrm{D}_{2}$ (Fig. 8) e em Z para o flanco esquerdo, mostrando que:

- Pelo menos durante a inclusão nas bordas, onde se caracteriza o padrão sigmoidal, as albitas tiveram um estágio de crescimento sin-dobramento $\mathrm{D}_{2}$.

- O padrão sigmoidal não pode ter sido gerado pela rotação de cristais inequidimensionais crescidos com orientações variadas, em função de achatamento homogêneo (encurtamento perpendicular a $S_{2}$ ), visto 


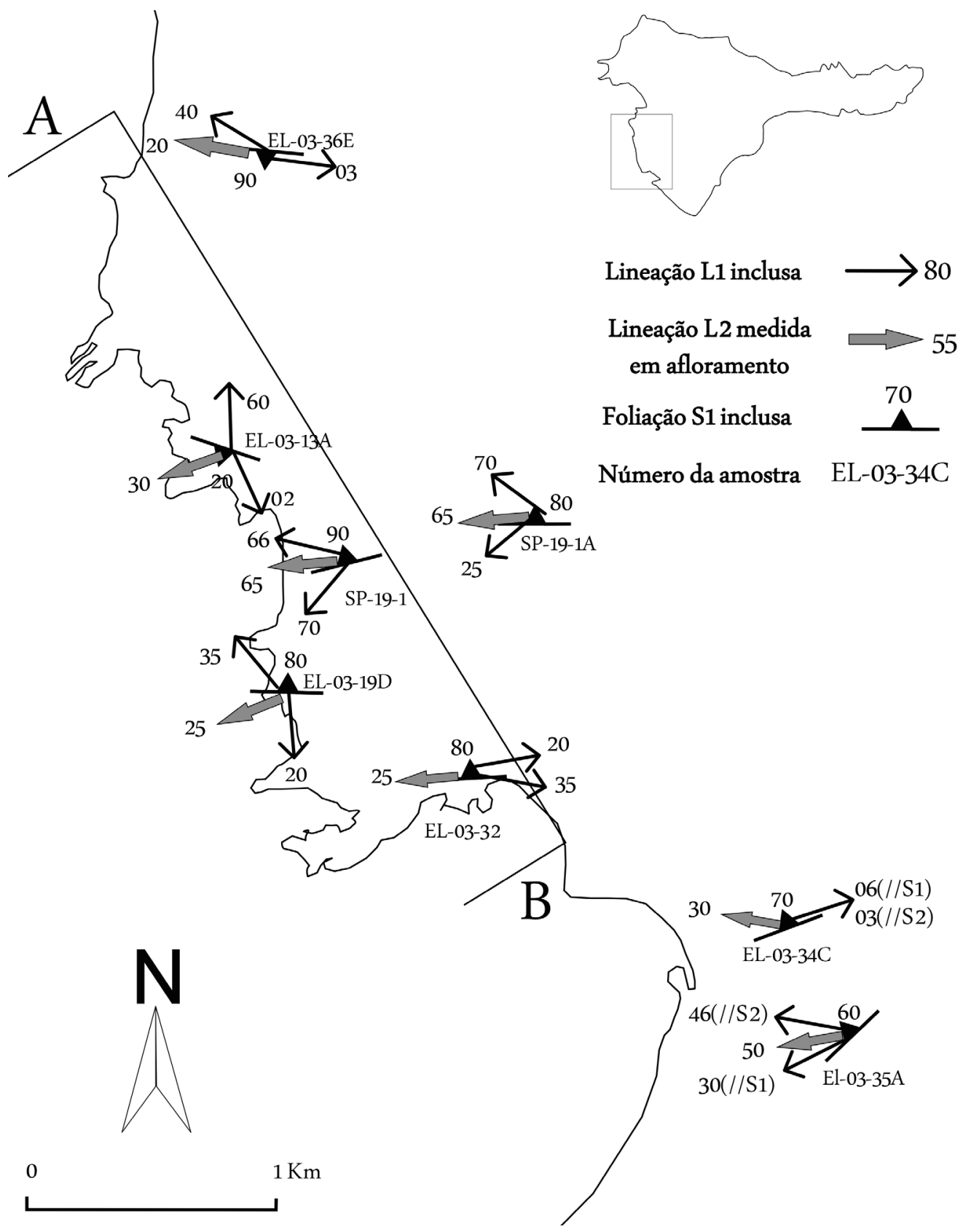

Figura 10 - Mapa da região de Stinker Point, com as orientações das medidas de $S_{1}$ inclusa, $L_{1}$ inclusa e $L_{2}$ em campo. AB indica a posição do perfil (Fig. 9) no mapa.
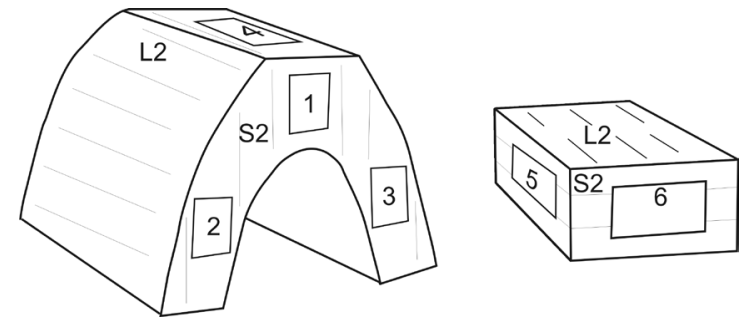

Figura 11 - Ilustração das diferentes posições de cortes das lâminas delgadas estudadas: (a) em relação à charneira (1) e flancos de dobras $D_{\text {, }}$; (b) paralela (5) ou perpendicular (6) à lineação mineral $\left(L_{2}\right)$. que seria esperado padrão sigmoidal com assimetrias opostas em um mesmo flanco.

RESULTADOS DA APLICAÇÃO NA ILHA ELEFANTE Os dados de lineação obtidos na platina universal são apresentados na forma de estereogramas, com as medidas já rotacionadas para sua posição geográfica no espaço (Fig. 12). As medidas obtidas para uma mesma lâmina não mostram muita dispersão (Fig. 13), apesar de serem medidos diferentes porfiroblastos, indicando homogeneidade da orientação de Li nesta escala. A dispersão em um único porfiroblasto é aproximadamente igual à dispersão em um conjunto de porfiroblastos em uma mesma lâmina. 


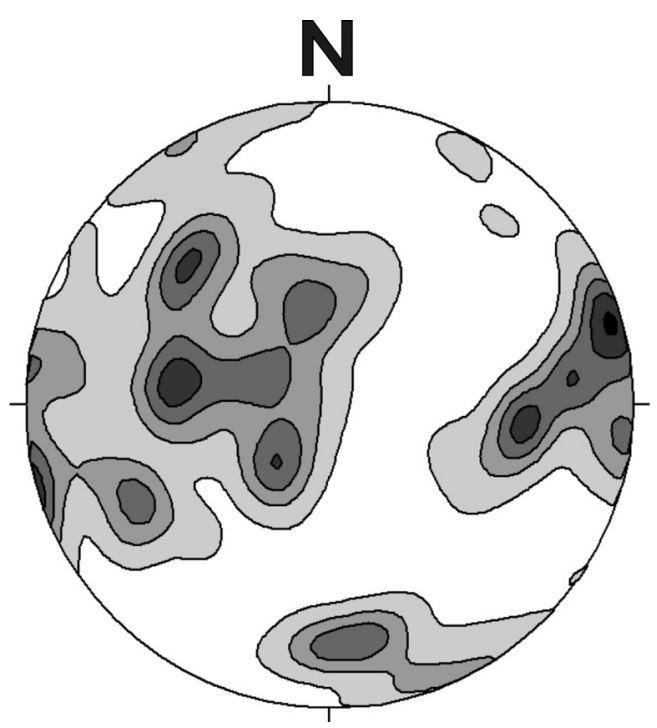

Figura 12 - Estereograma das medidas de lineações inclusas nos porfiroblastos de albita, para as oito amostras estudadas, corrigidas para o norte verdadeiro. As isolinhas marcam intervalos de percentagem de $5 \%$. Número de medidas $=840$.

No caso da região estudada na Ilha Elefante, as relações microtectônicas sugerem que a lineação $\mathrm{L}_{1}$, pré-dobrameto $\mathrm{D}_{2}$, deve ter tido suas orientações modificadas principalmente através de rotação em torno dos eixos de dobras $\mathrm{D}_{2}$.

As duas amostras de dobras com medidas de $\mathrm{L}_{1}$ nos dois flancos apresentaram resultados similares. A amostra EL-03-13-A corresponde a uma estrutura sin- formal com ângulo interflancos de $45^{\circ}$. As medidas de $\mathrm{Si}\left(=\mathrm{S}_{1} / / \mathrm{S}_{0}\right.$, inclusa no porfiroblasto) revelam um angulo interflancos de $120^{\circ}$, interpretado como estágio de apertamento da dobra no momento do início da blastese do porfiroblasto de albita. As medidas de Li fornecem o valor de $355 / 60$ no flanco sul e 155/02 no flanco norte. As medidas de Li obtidas são coerentes com a rotação de uma lineação em torno de um eixo 250/30, que corresponde aproximadamente ao eixo de dobras $\mathrm{D}_{2}$ medido neste ponto.

A amostra EL-03-19-D também corresponde a uma estrutura sinformal e mostra uma atitude preferencial de $L_{1}$, em 175/20 para o flanco norte e de 320/35 para o flanco sul. A diferença dos valores medidos nos dois flancos pode ser explicada pela rotação de $\mathrm{L}_{1} \mathrm{em}$ torno de um eixo com atitude aproximadamente 250/20, que corresponde bem com as medidas dos eixos das dobras $\mathrm{D}_{2}(248 / 25)$ neste afloramento.

As amostras SP-19-1 e SP-19-1A são duas amostras do mesmo ponto com cortes perpendiculares a foliação $S_{2}$, um paralelo a lineação $L_{2}$ (e conseqüentemente ao eixo $\mathrm{D}_{2}$ ) e outro perpendicular. Para estas amostras foram obtidas orientações similares, sendo $220 / 70$ e 250/25, para a primeira e $222 / 70$ e 230/35, para a segunda. Em conjunto guardam uma orientação que varia do rumo 220 a 250 , e caimentos entre 70 e 25. Atribui-se as diferenças encontradas a possíveis micro dobramentos responsáveis pelo giro da $\mathrm{L}_{1}$ antes do crescimento dos porfiroblastos de albita.

A amostra EL-03-32 é uma dobra assimétrica $\mathrm{D}_{2}$, com duas lâminas feitas no mesmo flanco, os máximos de $\mathrm{L}_{1}$ obtidos foram 100/35 e 080/20. Ambas são perpendiculares ao eixo de dobras $\mathrm{D}_{2}$ e apresentam o padrão normal da região de Stinker Point para a relação angular entre $\mathrm{S}_{1}$ e $\mathrm{S}_{2}$, ou seja, uma situação de flanco sul de sinforma. Os máximos de $\mathrm{L}_{1}$ similares é esperado pois as duas lâminas foram feitas nos flancos longos,

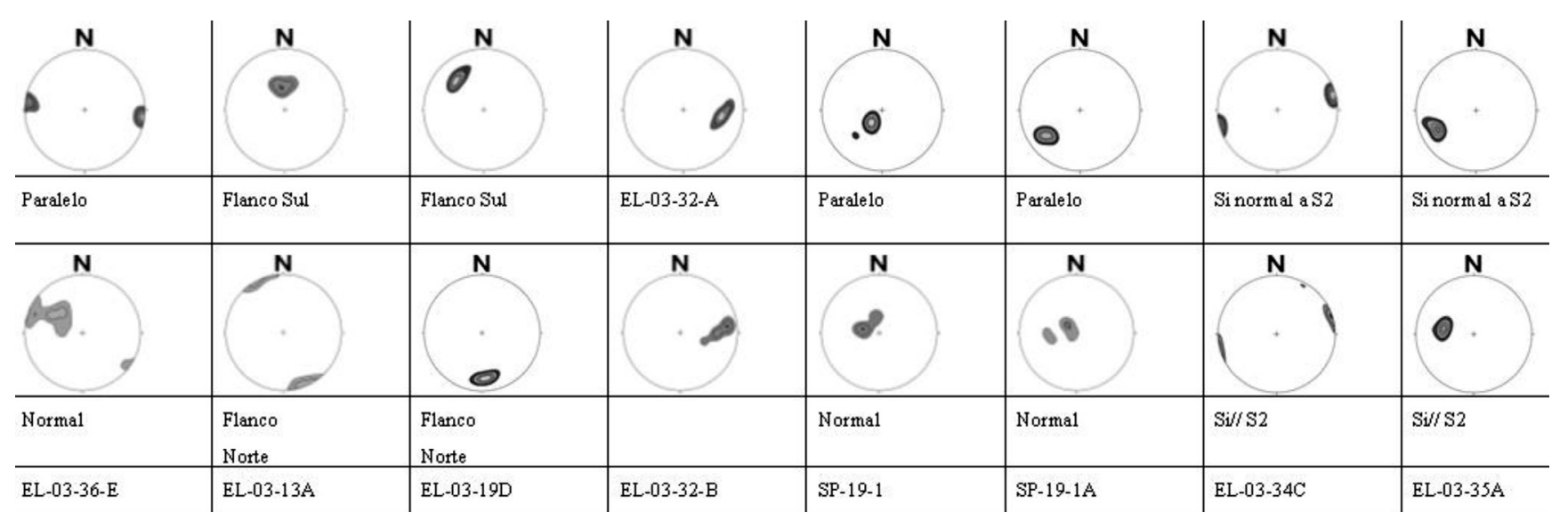

Figura 13 - Estereogramas das orientações geográficas das medidas de $L_{1}$ inclusa, obtidas nas amostras utilizadas neste trabalho. Para as amostras com dobra $D_{2}$ (EL-03-13A e EL-03-19D) os cortes são perpendiculares ao eixo da dobra, sendo indicados os flancos a que pertencem (ambas são estruturas sinformais, centimétricas). Para as amostras EL-03-34C e EL-03-35 um dos estereogramas corresponde às leituras feitas em porfiroblastos com Si perpendicular a $S_{2}$ e o outro para porfiroblastos com Si subparalelo a $S_{2}$. Para as demais amostras é dada a posição do corte em relação à orientação geral do eixo de dobras $D_{2}$ no local amostrado (normal ou paralela). As isolinhas marcam intervalos de $10 \%$. 
com a mesma assimetria.

As amostras EL-03-34C e EL-03-35 são dobras $\mathrm{D}_{2}$, sendo as lâminas estudadas referentes às zonas de charneira. As medidas de Li foram feitas separadamente para $\mathrm{Si}\left(=\mathrm{S}_{1}\right)$ paralelo e perpendicular a $\mathrm{S}_{2}$. Assim, há dois conjuntos distintos de medidas para cada uma destas amostras. Para a amostra EL-03-34C os valores obtidos são praticamente idênticos (75/06 e 71/03), sendo esta direção a mesma do eixo $\mathrm{D}_{2}$ medido no local (250/50), porém com caimento no sentido oposto. Como os dois conjuntos de medidas representam Si nas posições de flanco e charneira $\mathrm{D}_{2}$, então é provável que o eixo de rotação de $\mathrm{Si}$ (consequentemente de Li), tenha sido paralelo à direção medida (aproximadamente no rumo 70, com caimento suave). Isto sugere que estas dobras $\mathrm{D}_{2}$ deveriam ter eixos subhorizontais nesta direção e que na continuidade da deformação $\mathrm{D}_{2}$ foram rotacionados na matriz, conduzindo à configuração geral encontrada, que é o eixo das dobras paralelo à lineação de estiramento $\left(\mathrm{E}_{2} / / \mathrm{L}_{2}=250 / 35\right)$. A amostra EL-03-35 apresenta máximo de $\mathrm{Li}=243 / 30$, para $\mathrm{Si}\left(=\mathrm{S}_{1}\right)$ perpendicular a $\mathrm{S}_{2}$, e $280 / 46$ para $\mathrm{Si}\left(=\mathrm{S}_{1}\right)$ paralela a $\mathrm{S}_{2}$. Os valores encontrados são compatíveis com a rotação de $\mathrm{L}_{1}$ em torno do eixo $\mathrm{D}_{2}$ local.

A amostra EL-03-36-E mostra dois máximos de Li (097/03 e 301/40). A origem da diferença nos valores medida nos dois diferentes cortes pode ser explicada por diferentes estágios de rotação de Li no início da deformação $\mathrm{D}_{2}$, antes de ser englobada pelo porfiroblasto e, também, devido à rotação local dos porfiroblastos de albita durante $\mathrm{D}_{2}$.

Nas amostras estudadas, as orientações médias de $\mathrm{L}_{1}$ inclusa nos porfiroblastos de albita apresentam uma grande dispersão (Fig. 14). Apesar desta grande dispersão dos dados e do pequeno número de amostras, algumas conclusões quanto à orientação de $\mathrm{L}_{1}$ na porção sul da ilha podem ser extraídas: (a) A observação direta das inclusões com o auxílio da platina universal assegura que os porfiroblastos de albita preservam em seu interior uma lineação definida pela orientação preferencial de minerais inequidimensionais (principalmente epidoto); (b) $\mathrm{O}$ padrão disperso de $\mathrm{L}_{1}$ inclusa nos porfiroblastos tem similaridade com o encontrado na porção norte (Fig. 6) da ilha, onde $\mathrm{D}_{2}$ não obliterou totalmente as estruturas $\mathrm{D}_{1}$; (c) A maioria das medidas de lineação inclusa nos porfiroblastos é diferente da lineação mineral (Lm) existente na matriz; (d) A grande dispersão das Li deve refletir a rotação de $\mathrm{L}_{1}$ nos estágios iniciais do dobramento $\mathrm{D}_{2}$; (e) As medidas de Li obtidas para diferentes flancos de dobras fornecem valores coerentes com a rotação de uma lineação em torno de um eixo paralelo ao eixo de dobras $\mathrm{D}_{2}$.

Desta forma, a dispersão de $\mathrm{Li}^{2}$ é interpretada como efeito dos estágios iniciais da deformação $\mathrm{D}_{2}$ que causou rotações variadas de $\mathrm{L}_{1}$, antes do crescimento dos porfiroblastos de albita. Adicionalmente, é possível que ocorram pequenas rotações locais dos porfiroblastos de albita, segundo eixos diferentes o eixo de dobras $\mathrm{D}_{2}$, como por exemplo, relacionadas ao cisalhamento sinistral tardi $\mathrm{D}_{2}$ (Trouw et al. 2000) e/ou acomodações locais em torno de feições lenticulares ou, ainda, devido a interferência entre porfiroblastos em contato mútuo.

A análise da distribuição das lineações medidas, visualizadas em estereograma com o eixo $\mathrm{D}_{2}$ na vertical, corrobora esta interpretação. A figura 15 é um estereograma onde o eixo $\mathrm{D}_{2}(250 / 35)$ foi rotacionado para uma posição vertical, aplicando-se esta mesma rotação às lineações medidas. Com exceção de uma medida que é coincidente com o eixo $\mathrm{D}_{2}$ (cai no centro do

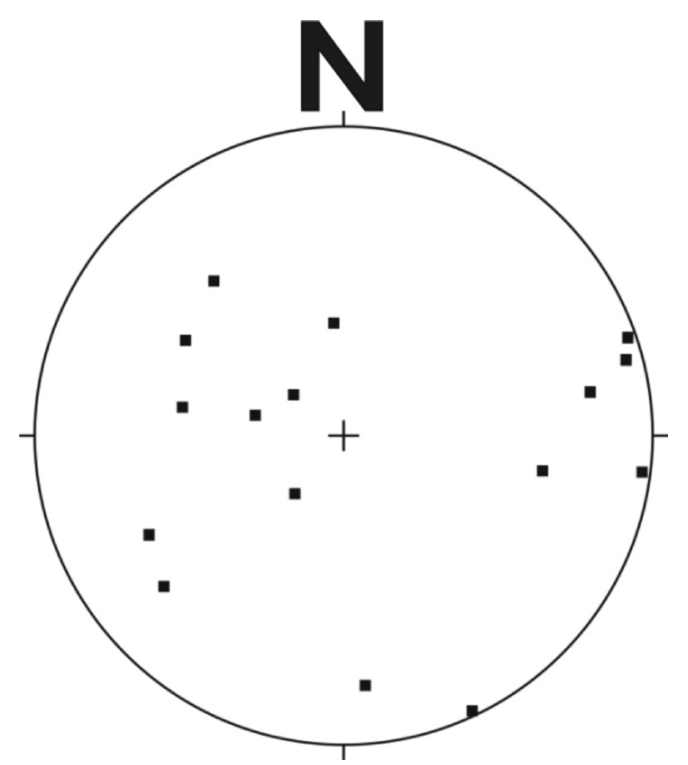

Figura 14 - Estereograma das medidas de lineações inclusas nos porfiroblastos de albita, para as oito amostras estudadas, corrigidas para o norte verdadeiro.

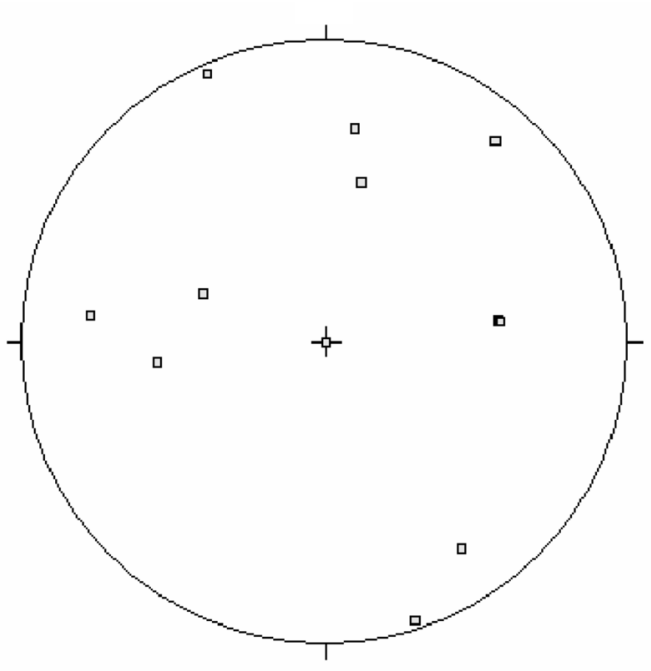

Figura 15 - Estereograma representando o eixo $D_{2}(250 / 35)$ rotacionado para a posição vertical, com as medidas de Li (ilustrados na Fig. 14) submetidas à mesma rotação. 
diagrama), a distribuição das medidas mostra que, a $\mathrm{Li}$ faz ângulo médio a alto com o eixo $\mathrm{D}_{2}$, o que conduz à interpretação de que a orientação original de $\mathrm{L}_{1}$ apresentava alta obliqüidade com este eixo. Se a orientação de $\mathrm{L}_{1}$ no momento de ser incluída em cada porfiroblasto fosse constante, as medidas deveriam se concentrar em um semicírculo em torno do centro do eixo. A dispersão das medidas não permite ajustá-las a um semicírculo, por isso são interpretadas como tendo orientações variadas já antes da inclusão, em grande parte devido à deformação $\mathrm{D}_{2}$. Admite-se, todavia, que em alguns casos possam ser atribuídas a rotações locais dos porfiroblastos, após inclusão. Como, de uma forma geral, a deformação tenderá a conduzir os elementos lineares para o plano (e lineação) atrator da deformação mais nova, pode-se admitir que as atitudes de Li mais próximas da orientação original de $\mathrm{L}_{1}$ devem ser as mais distantes de $\mathrm{S}_{2}$ e $\mathrm{L}_{2}$. Neste caso, os valores de Li 320/34, 172/18 e 155/horizontal (Fig. 13) devem representar as medidas mais próximas da orientação original de $\mathrm{L}_{1}$, podendo-se concluir que a $\mathrm{L}_{1}$ tinha direção entre $\mathrm{N} 40 \mathrm{~W}$ e N8W. Esta direção é coerente com o modelo tectônico proposto para a área que indica subducção de norte para sul durante $\mathrm{D}_{1}$ (Trouw et al. 2000).

CONCLUSÕES $O$ reconhecimento de minerais orientados em arranjo linear no interior de porfiroblastos é possível e, em alguns casos, estas lineações podem ter suas orientações originais recuperadas, utilizando-se da platina universal, conforme metodologia apresentada neste trabalho.

Para cada modelo de deformação, a depender da quantidade de giro e da posição inicial da lineação, o padrão de Li em estereograma definirá círculos ou segmentos de círculos em torno do eixo de rotação, ou seja, guirlandas desenhando círculos mínimos. Nos casos de deformações envolvendo principalmente dobramentos, o eixo de rotação é o eixo da dobra.

A aplicação do método para o caso da porção sul da Ilha Elefante (South Sheetland Islands, Antártica) mostrou que as lineações resgatadas no interior dos porfiroblastos apresentam um padrão diferente da lineação mineral na matriz $\left(\mathrm{L}_{2}\right)$, corroborando a interpretação de que as lineações inclusas nos porfiroblastos correspondem a $\mathrm{L}_{1}$. Além disso, indica que a orientação preferencial de $\mathrm{L}_{1}$ é NNW, coerente com o modelo de subducção proposto para a área (Trouw et al. 2000).

Agradecimentos A Rudolph Trouw pelo empréstimo das amostras que foram utilizadas neste trabalho e ao CNPq pela concessão de bolsa de mestrado concedida a FGGA (Processo 134173/04). As amostras foram coletadas com suporte do Programa Antártico Brasileiro, ficando aqui os agradecimentos às tripulações do $\mathrm{Na}$ pOc Ary Rongel.

\section{Referências}

Aerden D.G.A.M. 2004. Correlating deformation in Variscan NW-Iberia using porphyroblasts; implications for the Ibero-Armorican Arc. J. Struct. Geol., 26(1):177-196.

Bell T.H. 1985. Deformation partioning and porphyroblast rotation in metamorphic rocks: a radical interpretation. J. Metam. Geol., 3(1):109-118.

Bell T.H. 1986. Foliation development and refraction in metamorphic rocks: reactivation of earlier foliations and decrenulation due to shifting patterns of deformation partioning. J. Metam. Geol., 4(4):421-444.

Bell T.H. \& Johnson S.E. 1989. Porphyroblast inclusion trails: the key to orogenesis. J. Metam. Geol., 7(3):279310 .

Bell T.H., Johnson S.E., Davis B., Forde A., Hayward N., Willkins C. 1992. Porphyroblast inclusion-trail orientation data: eppure non son girate! J. Metam. Geol., 10(3):295-307.

Bell T.H. \& Chen A. 2002. The development of spiralshaped inclusion trail during multiple metamorphism and folding. J. Metam. Geol., 20(4):397-412.

Bell T.H. \& Kim H.S. 2004. Preservation of Acadian deformation and metamorphism through intense Alleghanian shearing. J. Struct. Geol., 26(9):1591-1613.

Cihan M. 2004. The drawbacks of sectioning rocks relative to fabric orientations in the matrix: A case study from the Robertson River Metamorphics (Northern Queensland, Australia). J. Struct. Geol., 26(12):2157-2174.

Evins P.M. 2005. A 3D study of aligned porphyroblast inclusion trails across shear zones and folds. J. Struct. Geol., 27(14):1300-1314.

Fossen H. \& TikoffB. 1998. Extended models of transpression and transtension, and application to tectonic settings. In: Holdswort R.E., Strachan R.A., Dewey J.F. (eds.) 1998. Continental Transpressional and Transtensional Tectonics. Geological Society, Special Publications, London, 135:15-33.

Ghosh S.K. \& Ramberg H. 1976. Reorientation of inclusions by combination of pure shear and simple shear. Tectonophysics, 34(1):1-70.

Grunow A.M., Dalziel I.W.D., Harrison T.M., Heizler M.T. 1992. Structural Geology and geochronology of subduction complexes along the margin of Gondwanaland: New data from the Antarctic Peninsula and southernmost Andes. Geol. Soc. Am. Bull., 104(11):1497-1514.

Hickey K.A. \& Bell T.H. 1999. Behaviour of rigid objects during deformation and metamorphism: a test using schists from the Bolton syncline, Connecticut, USA. $J$. Metam. Geol., 17(2):211-228.

Hossak J.R. \& Cooper M.A. 1986. Collision tectonics in the Scandinavian Caledonides. In: Coward M.P. \& Ries A. (ed.) Collision Tectonics. Geological Society, Special Publication, Blackwell, London, 19:287-304.

Holcombe R.J. \& Little T.A. 2001. A sensitive vorticity gauge using rotated porphyroblasts, and its application to rocks adjacent to the Alpine Fault, New Zealand. $J$. 
Struct. Geol. 23(7):979-989.

Jiang D. \& Willians P.F. 2004. Reference frame, angular momentum, and porphyroblast rotation. J. Struct. Geol., 26(12):2211-2224.

Johnson S.E. 1999. Porphyroblast microstructures: A review of current and future trends. Am. Mineral., 84(11/12):1711-1726.

Kraus J. \& Willians P.F. 2001. A new spin on 'non-rotating' porphyroblasts: implications of cleavage refraction and reference frames. J. Struct. Geol., 23(6/7):963-971.

Marques F.O., Taborda R.M., Antunes J.V. 2005. 2D rotation of rigid inclusions in confined bulk simple shear flow: a numerical study. J. Struct. Geol., 27(10):2171-2180.

Passchier C.W. 1987. Stable positions of rigid objects in non-coaxial flow - a study in vorticity analysis. J. Struct. Geol., 15(6):895-910.

Passchier C.W., Trouw R.A.J., Zwart H.J., Vissers R.L.M. 1992. Porphyroblast rotation: eppur si muove? J. Metam. Geol., 10(3):283-294.

Passchier C.W. \& Trouw R.A.J. 1996. Microtectonics. Springer-Verlag, Nova York 283 p.

Passchier C.W. \& Trouw R.A.J. 2005. Microtectonics. Springer-Verlag, Nova York 366 p.

Ramsay J. 1962. The geometry and mechanics of formation of "similar" type folds. J. Geol., 70:309-327.

Schoneveld C. 1977. A Study of some typical inclusion paterns in strongly paracrystalline-rotated garnets. Tectonophysics, 39(1/3):453-471.

Simões L.S.A., Trouw R.A.J., Valeriano C.M., Matsuo E.S.O. 2003. Padrão de inclusões em porfiroblastos sintectônicos a dobramento. In: SBG, Simpósio Nacional de Estudos Tectônicos, 12, Búzios, Atas, p.176-179.

Trouw R.A.J., Ribeiro A., Paciullo F.V.P. 1986. Contribuição à Geologia da Ilha Elefante, Ilhas Shetland do Sul. Anais da Acad. Bras. Ciências, Rio de Janeiro, 58(supl.):157169.
Trouw R.A.J., Simões L.S.A., Valadares C. 1998. Variation in mineral chemical composition across a subduction complex with Sambagawa-type metamorphism, South Shetland Islands, Antarctica. Pesquisa Antártica Brasileira, 3:133-169.

Trouw R.A.J., Passchier C.W., Valeriano C.M., Simões, L.S.A., Paciullo F.V.P., Ribeiro A. 2000. Deformational evolution of a Cretaceous subdution complex: Elephant Island, South Shetland Islands, Antarctica. Tectonophysics, 319(2):93-100.

Uhlein A. 1991. Transição cráton-faixa dobrada: um exemplo do Cráton do São Francisco e da Faixa Araçuaí (ciclo Brasiliano) no Estado de Minas Gerais. Tese de Doutoramento, Instituto de Geociências, Universidade de São Paulo, 295 p.

Valeriano C.M., Dardenne M.A.F.M., Simões L.S.A., Seer H.J. 2004. A Evolução Tectônica da Faixa Brasília. In: Mantesso Neto V., Bartorelli A., Carneiro C.D.R., Brito Neves B.B. de (eds.) O desvendar de um continente: a moderna geologia da América do Sul e o legado da obra de Fernando Flávio Marques de Almeida. São Paulo: Beca, p. 575-593.

Visser P. \& Manckelow N.S. 1992. The rotation of garnet porphyroblast around a single fold, Lukmainer Pass, Central Alps. J. Struct. Geol., 14(10):1193-1202.

Willians P.F. \& Jiang D. 1999. Rotating garnets. J. Metam. Geol., 17(4):367-378.

Zwart H.J. 1962. On the determination of polimetamorphic mineral associations and its application to the Bosot area (Central Pyrenees). Geologische Rundschau, Stuttgart, 52(1):38-65.

Manuscrito ID 10134

Submetido em 26 de dezembro de 2007 Aceito em 17 de agosto de 2009 